\title{
Comparison of Statin Adherence Among Beneficiaries in MA-PD Plans Versus PDPs
}

\author{
Kyoungrae Jung, PhD; A. Marshall McBean, MD, MSc; and Jee-Ae Kim, MPP
}

\begin{abstract}
BACKGROUND: Medicare Part D, which provides prescription drug coverage to Medicare beneficiaries, is delivered through either Medicare Advantage prescription drug (MA-PD) plans or stand-alone prescription drug plans (PDPs). MA-PD plans cover both drug therapy and other medical services, whereas PDPs provide prescription drug coverage only. Because of the potential substitutability between prescription drugs and other medical services, MA-PD plans may make greater efforts to improve enrollees' adherence to recommended medications than PDPs. Prescription drug benefits are more generous in MA-PD plans than in PDPs.
\end{abstract}

OBJECTIVE: To assess statin adherence, comparing Medicare beneficiaries in MA-PD plans with those in PDPs.

METHODS: We used records from the Chronic Condition Warehouse 2007 Prescription Drug Event (PDE) file, associated Plan Characteristics files, and the Beneficiary Summary File (BSF) for a $5 \%$ random sample of Medicare beneficiaries. The study sample comprised Medicare beneficiaries aged 65 years or older in $\mathbf{2 0 0 6}$ who filled at least 1 prescription for a statin during 2007, excluding beneficiaries with low-income subsidy or end-stage renal disease and those without both Medicare Part A and Part B enrollment in 2007. Medication adherence was measured by medication possession ratio (MPR), defined as the sum of days supply for all statin prescriptions filled in 2007 minus the days supply that would have carried over into 2008 from the final 2007 prescription filled, divided by the total number of days from the fill date of the first statin prescription to December 31, 2007. A binary indicator of good adherence was defined as MPR exceeding $80 \%$. Propensity-score matching was used to reduce differences in observed characteristics of enrollees in MA-PD plans and PDPs. The propensity score was based on sociodemographic characteristics and health risk measures, including Hierarchical Condition Category (HCC) scores.

RESULTS: In the unmatched sample, the mean MPR was $70.57 \%$ for MA-PD enrollees versus $70.54 \%$ for PDP enrollees $(P=0.780)$, and the proportion of enrollees with good adherence was $46.7 \%$ for MA-PD plans versus 46.9\% for PDPs $(P=0.262)$. In the matched sample, statin adherence was slightly better among MA-PD enrollees than PDP enrollees. Mean MPRs were $70.80 \%$ and $69.44 \%$, and the percentages of enrollees with good adherence were $47.0 \%$ and $45.3 \%$ in MA-PD plans and PDPs, respectively (both $P<0.001$ ).

CONCLUSIONS: During an early year of the Part D program, MA-PD enrollees had slightly better adherence to statin therapy than PDP enrollees. While the difference was statistically significant, it was very small and unlikely to lead to clinically meaningful consequences. Less than one-half of MA-PD and PDP enrollees had good adherence in statin use, suggesting room for improvement in both types of Part $D$ plans. Continuing evaluations of adherence in diverse therapy classes are needed for Medicare Part D beneficiaries.

J Manag Care Pharm. 2012;18(2):106-15

Copyright $\odot 2012$, Academy of Managed Care Pharmacy. All rights reserved.

\section{What is already known about this subject}

- Medicare Part D services are delivered through 2 different types of private plans: Medicare Advantage prescription drug (MA-PD) plans or stand-alone prescription drug plans (PDPs). MA-PD plans cover both drug therapy and other medical services, whereas PDPs provide prescription drug coverage only.

- An economic model suggests that an optimal level of medication use, which maximizes consumers' utility or benefit, will be achieved when one insurer is responsible for covering all types of substitutable services. Observational studies have suggested that pharmacy therapy and nondrug medical services may be substitutable. Goldman et al. (2006) found that medication possession ratio (MPR) of less than $80 \%$ for statin therapy was associated with increases in hospitalizations and emergency room visits. Gibson et al. (2006) reported that MPR greater than 80\% for statin therapy was related to fewer coronary heart disease-related hospitalizations, all-cause hospitalizations, and emergency room visits.

- These findings suggest that health plans that cover both drug and medical services may have an incentive to improve medication adherence in an attempt to reduce medical costs. MA-PD plans offer more generous drug benefits than do PDPs. However, little is known about whether Medicare beneficiaries in MA-PD plans, which cover different types of substitutable services, have better medication adherence than those in PDPs.

\section{What this study adds}

- Analysis of data from the 5\% random sample of Medicare Part D enrollees based on propensity-score matched sample subgroups indicated that the mean MPR for statin therapy among MA-PD plan enrollees exceeded that of PDP enrollees by 1.36 percentage points (70.80\% vs. $69.44 \%$ ). The proportion of MA-PD beneficiaries with good statin adherence (MPR more than 80\%) exceeded that of PDP enrollees by 1.7 percentage points (47.0\% vs. $45.3 \%$ ).

- The proportion of Part D enrollees who had good statin adherence in 2007 was less than 50\% in both MA-PD plans and PDPs.

- The primary study finding-clinically negligible differences in statin adherence between the 2 types of plans-did not support the hypothesis that enrollees in MA-PD plans, in which medical and pharmacy benefits are integrated, would have better medication adherence than enrollees in stand-alone PDPs. 
$\mathrm{M}$ edicare Part D, which was implemented as part of the 2003 Medicare Modernization Act (MMA), provides prescription drug coverage for Medicare beneficiaries. The Part D program was introduced to improve Medicare beneficiaries' access to prescription drugs, thereby potentially enhancing health outcomes of beneficiaries. In offering the Part D program, Medicare took a different approach than in the existing Part A and Part B programs, which provide coverage for hospital care and outpatient services. Medicare Part D services are delivered entirely through private plans, primarily Medicare Advantage prescription drug (MA-PD) plans or stand-alone prescription drug plans (PDPs).

MA-PD plans offer coverage for both pharmacy therapy and other types of medical services, while PDPs cover only prescription drugs. An economic model developed by Goldman and Philipson (2007) predicts that if a service is covered by an integrated insurer offering other services that are substitutable, its copayment will be lower than when the substitutable services are covered by other insurers because lowering copayment of the service helps decrease the use of other substitutable services. ${ }^{1}$ This prediction suggests that an optimal level of the service use, which maximizes consumers' utility or benefit, is likely to be achieved when only 1 insurer is responsible for covering these substitutable services. As a demonstration of this relationship, albeit in the opposite direction, Chandra et al. (2010) found that increased cost sharing for physician services and prescription drugs by a supplemental insurer among Medicare beneficiaries was associated with less use of those services but more hospitalizations. ${ }^{2}$ This study also reported that the supplementary insurer benefited from decreased prescription drug utilization and the shifting of the costs to patients through increased copayments, while Medicare bore the costs of increased hospitalizations. ${ }^{2}$

Therefore, beneficiaries in MA-PD plans, which cover different types of substitutable services, may have better medication adherence than those in PDPs, if MA-PD plans act on the potential cost-offsetting effects-decreased use of nondrug medical services from the increased drug adherence-and make efforts to enhance enrollees' adherence to prescribed medications. This perception would be contrary to the results reported in the RAND Health Insurance Experiment (HIE), which showed that increased cost sharing reduced the use of services without affecting health outcomes. ${ }^{3}$ However, the RAND HIE excluded adults aged 65 years or older.

In fact, MA-PD plans have offered more generous drug benefits than PDPs by subsidizing prescription drug coverage using the payments for coverage of other medical services. ${ }^{4}$ In $2007,75 \%$ of MA-PD plans covering $80 \%$ of MA-PD enrollees offered an enhanced plan (which is more generous than the standard or actuarially equivalent plan), while $48 \%$ of PDPs covering 20\% of PDP enrollees provided such a plan. ${ }^{5}$ Also,
$33 \%$ of MA-PD plans offered partial to full coverage for the gap period, during which beneficiaries are responsible for full medication costs, while $28 \%$ of PDPs provided some gap coverage. $^{5}$ About $90 \%$ of MA-PD plans with $95 \%$ of total MA-PD enrollment charged no deductibles in 2007, while $60 \%$ of PDPs (54\% of PDP enrollees) had no deductibles. ${ }^{5}$

The literature indicates that the relationship between drug coverage benefits and medication adherence is not always clear. ${ }^{6}$ A report from the Kaiser Family Foundation (Hoadley et al. 2008) showed that $15 \%$ of Medicare beneficiaries entering a coverage gap in 2007 stopped taking their medications, based on an analysis of community pharmacy data. ${ }^{7}$ Fung et al. (2010), using claims data, assessed adherence to oral antidiabetic, antihypertensive, and antihyperlipidemic drugs among Medicare beneficiaries with diabetes in an MA-PD plan. ${ }^{8}$ The study reported that drug adherence in 2006, defined as having drug supply more than $80 \%$ of the days in the year, was lower among those without gap coverage than those with gap coverage by about 5 percentage points for antidiabetic and antihypertensive drugs and by 8 percentage points for antihyperlipidemic drugs. ${ }^{8}$ However, a survey by Tseng et al. (2004) found that Medicare + Choice beneficiaries who reached an annual dollar cap in drug coverage were more likely to take less medication than prescribed but no more likely to discontinue a medication compared with beneficiaries who had no cap. ${ }^{9}$ While the findings from prior literature vary depending on data collection methods, therapeutic classes examined, or outcome measures used (e.g., probability of use, compliance, and discontinuation), a review by Gemmill et al. (2008) reported that some studies examining compliance (not persistency or probability of use) found that higher cost sharing is negatively associated with compliance to treatment. ${ }^{10}$

MA-PDs may thus have expected to improve drug adherence through their benefit structure, along with their carecoordination efforts. Our study examines whether MA-PD enrollees have better medication adherence than PDP enrollees in the use of statins. Several prior studies evaluated medication adherence among Medicare Part D enrollees. However, most of the previous studies were limited to examining medication adherence at the MA-PD setting only or whether the overall use of prescription drugs increased after the introduction of the Part D program. ${ }^{11,12}$ No research has assessed differences in medication adherence between enrollees in MA-PD plans and PDPs.

Our analysis focused on statin use because statins are the vastly dominant group of drugs in the antihyperlipidemic therapeutic class, with the highest amount of reimbursement ( $\$ 5.3$ billion), or $8.5 \%$ of all Part D expenditures in $2007 .{ }^{13}$ Statin treatment is a critical element of preventing and managing coronary heart disease (CHD), which is a common chronic condition in the United States, whose cost is estimated to be 
about $\$ 165.4$ billion. ${ }^{14-16}$ Previous studies indicate that a high level of statin adherence is related to a decrease in the use of other medical services. For example, Goldman et al. (2006) reported that full statin adherence, defined as medication possession ratio (MPR) of at least $80 \%$, was associated with 357 fewer hospitalizations and 168 fewer emergency room visits per 1,000 high-risk patients, compared with MPR less than $80 \%{ }^{17}$ The study indicated that adherence among low-risk patients was associated with 42 fewer hospitalizations and 21 fewer emergency room visits. ${ }^{17}$ Gibson et al. (2006) also found that improved statin adherence was related to fewer CHD-related hospitalizations. ${ }^{18}$

Thus, we hypothesized that MA-PD plans may have greater incentives than PDPs to improve statin adherence among their enrollees to reduce total medical costs. Using data from a random sample of Medicare Part D beneficiaries living in all 50 states and the District of Columbia, we examined differences in statin use between MA-PD and PDP enrollees. The study was conducted under Institutional Review Board Project Number 0712E23765 of the University of Minnesota.

\section{Methods}

\section{Data Sources and Study Sample}

The primary data sources for the study were the 2007 Medicare Part D Prescription Drug Event (PDE) file for the 5\% sample of beneficiaries, the associated Plan Characteristics files, and Beneficiary Summary Files (BSF) from the Medicare-supported Chronic Condition Warehouse (CCW). Both the PDE and BSF include encrypted beneficiary identification numbers provided by CCW, and the PDE and Plan Characteristics files contain encrypted Part D plan identifiers. The PDE data contain information about each prescription drug filled by Medicare Part D enrollees, including the National Drug Code (NDC) number of the dispensed drug, the date dispensed, the days supply, and a CCW-derived variable, "benefit phase." Specifically, the CCW uses drug expenditure information for each individual and benefit design information for the plan in which the beneficiary is enrolled to calculate for each pharmacy claim the benefit phase (e.g., deductible, pre-initial coverage limit [ICL], gap, or catastrophic) that covered that claim. The BSFs augment the PDE data by supplying beneficiaries' demographic characteristics (age, race, and gender); place of residence (ZIP code); and monthly Medicare Part A, Part B, and Part D enrollment status. From the Plan Characteristics files, we obtained Part D plan type information, as well as drug benefit structure information for the Part D plans (basic vs. enhanced; gap coverage vs. no gap coverage).

The study sample comprised Medicare Part D enrollees who filled at least 1 prescription for a statin in 2007 (Figure 1). Because the Part D data files include only pharmacy event information, not medical claims, we identified our study

\begin{tabular}{|l|l} 
TABLE 1 & \multicolumn{1}{c}{$\begin{array}{l}\text { Medi-Span } \\
\text { Identify }\end{array}$} \\
& \multicolumn{1}{c}{ GPI Codes Used to } \\
& \multicolumn{1}{c}{ Generic Names } \\
\hline PI Codes $^{\text {b }}$ & Atorvastatin calcium \\
\hline 94000 & Ezetimibe-simvastatin \\
394099 & Fluvastatin sodium \\
& Lovastatin \\
& Niacin-lovastatin \\
& Niacin-simvastatin \\
& Pravastatin sodium \\
& Rosuvastatin calcium \\
& Simvastatin \\
\hline
\end{tabular}

${ }^{a}$ Medi-Span Master Drug Data Base, version 2.5. Wolters-Kluwer Health, Indianapolis, IN; 2010.

${ }^{b}$ All drugs beginning with these 6-digit GPI codes were included. GPI = generic product identifier

sample based on statin use instead of a specific condition, such as hyperlipidemia. While it would be possible to obtain diagnosis information for fee-for-service beneficiaries (i.e., the PDP enrollees) if we used Part A and Part B claims data, no medical claims data are available to researchers for MA-PD enrollees.

We first identified all statin medications in the Medi-Span Master Drug Database version 2.5 (MDDB v2.5; Wolters Kluwer Health, Indianapolis, IN) using Generic Product Identifier (GPI) codes to determine the 11-digit NDC numbers in the 5-4-2 format developed by the National Council for Prescription Drug Programs for each statin-containing medication (Table 1). ${ }^{19}$ To identify statin users, we searched the Product Service ID field (11-character NDC number) in the Medicare PDE file using the list of NDC numbers for the statin medications. We then merged the PDE file of statin users with the BSF using the CCW-provided encrypted beneficiary identification number. Based on the Medicare enrollment and demographic data in the BSF, we limited the study sample to Medicare beneficiaries aged 65 years or older in 2006 who had both Part A and Part B coverage in 2007. We excluded beneficiaries who died in 2007, those with end-stage renal disease (ESRD), and low-income subsidy (LIS) beneficiaries, who may have different characteristics and drug utilization patterns than other Medicare beneficiaries. We then linked the file to the Part D Plan Characteristics file using the encrypted plan identifier. Using the Part D Plan Characteristics file and BSF, we excluded beneficiaries who were enrolled in Medicare cost or demonstration plans. We defined beneficiaries' plan membership (MA-PD vs. PDP), which is the main explanatory variable of interest, as being enrolled in either type of plan for all 12 months in 2007.

The ZIP code of residence of each beneficiary was linked to the 2000 U.S. Census summary file [SF] 3 to determine the median household income and percentage of the population with a college education in each ZIP code. The Centers for Medicare \& Medicaid Services (CMS) supplied Hierarchical Condition Category (HCC) scores for both MA-PD and PDP 


\section{FIGURE 1 Study Sample Selection Process for MA-PD Plan Enrollees and PDP Enrollees}

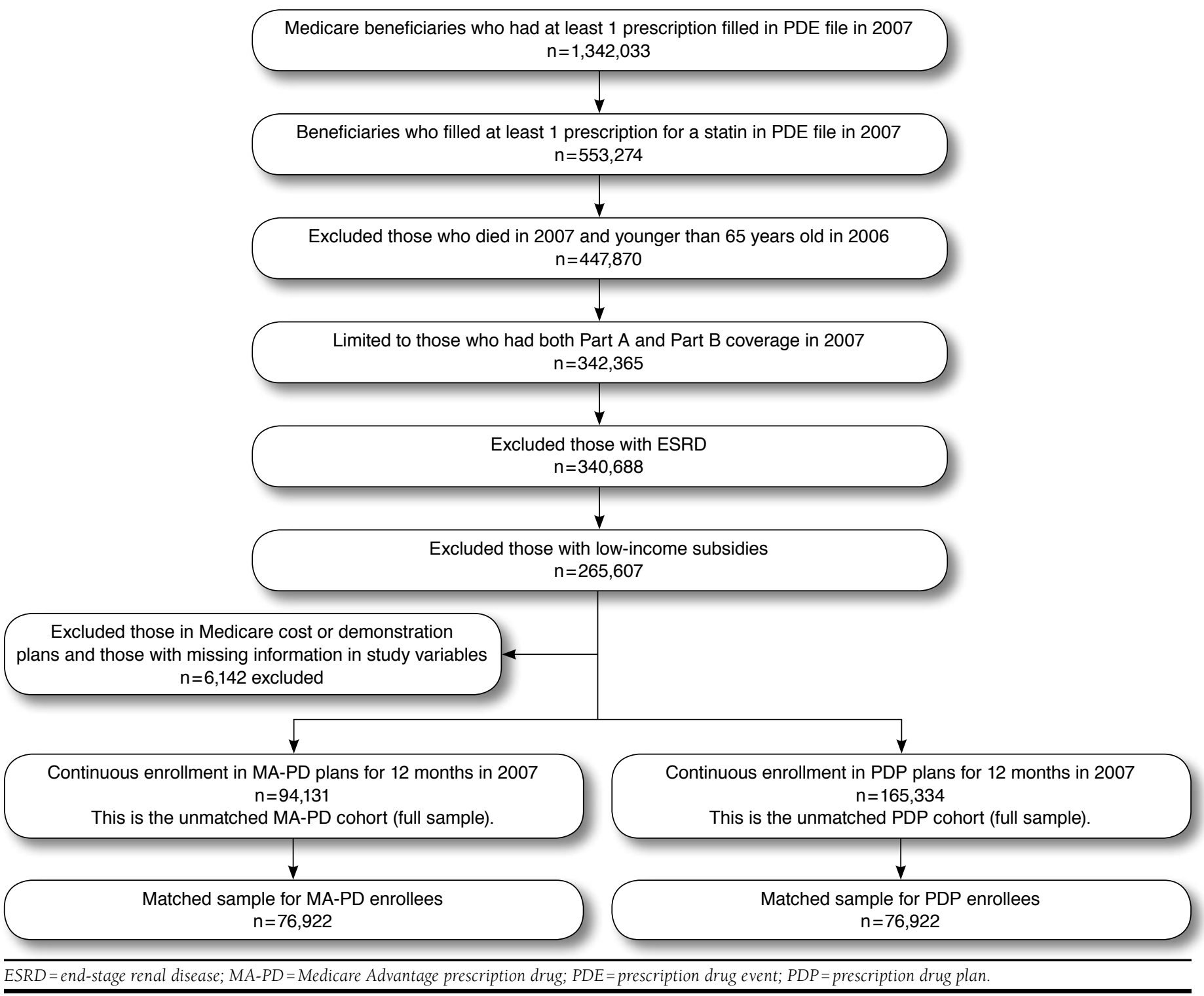

enrollees. ${ }^{20}$ We added this variable to the analytic file using the encrypted beneficiary identification number.

\section{Outcome Measures}

We measured medication adherence using the MPR and a binary indicator of good adherence. The denominator for the MPR was the number of days between the date of a beneficiary's first statin pharmacy claim in 2007 (index date) and December 31, 2007. To obtain the numerator of the MPR, we summed the number of days supplied for all statin claims in 2007 and subtracted the days supplied that would have carried over into 2008 from the last prescription in 2007. About 50\% of beneficiaries in both MA-PD plans and PDPs had an index statin fill in January, and more than $90 \%$ of beneficiaries in both groups began their statin use before June. The median values of the numerator and denominator were 233 and 335, respectively. This definition of MPR has been recommended as an appropriate measure to capture medication use for chronic conditions because it considers all early terminations as nonadherence. ${ }^{21}$ This MPR measure also has been reported as a good predictor of hospitalizations for diabetes. ${ }^{22}$ 
The second outcome measure was a binary indicator of good adherence. Following the prior literature, we defined good adherence as MPR greater than $80 \%{ }^{8,23-25}$ Pladevall et al. (2004) suggested that this categorical approach may be appropriate to examine whether poor adherence of medication is associated with worsened clinical health outcomes. ${ }^{26}$

\section{Analysis}

We used propensity score matching analysis for both outcome measures to address potential imbalances in enrollee characteristics between MA-PD plans and PDPs. Because Part D plan choice is voluntary, it is possible that relatively healthy beneficiaries select into an MA-PD. ${ }^{27}$ Propensity score matching partially accounts for this possibility by ensuring similar distributions in observable characteristics between the 2 groups being compared. ${ }^{28,29}$ We calculated each beneficiary's propensity score of enrolling in an MA-PD plan based on logistic regression.

We created our matched sample based on a one-to-one matching with the nearest neighbor method within the caliper of $0.01 .^{30}$ We evaluated similarities in covariates between MA-PD and PDP enrollees in the matched sample using the standardized difference, which is defined as the difference in means between the 2 groups divided by the square root of the average of their variances. ${ }^{31}$ Since this statistic is not a function of sample size, it has been often used in the literature to assess the balance in covariates in propensity score matching analysis. ${ }^{29,32,33}$ A standardized difference smaller than 10 implies no meaningful difference on observed characteristics between the 2 groups being compared. ${ }^{31}$ We obtained standard errors of the propensity score matching estimates based on bootstrapping with 500 repetitions.

Analyses were performed using SAS statistical package, version 9.2 (SAS Institute Inc., Cary, NC). STATA version 11 was used for propensity scare matching analysis (StataCorp LP, College Station, Texas). The a priori alpha level was 0.05.

Variables Used for Propensity-Score Matching. The variables included in the logistic regression model to construct propensity scores were demographic characteristics (age, gender, and race), socioeconomic variables (median income and percentage with a college education in the ZIP code of residence), U.S. Census Bureau region of residence, health risk measures, and benefit design characteristics of the Part D plans.

To capture health risk of beneficiaries, we used CMS-HCC scores, which are a health-risk measure used to adjust Medicare Advantage plan payment. These scores are constructed based on inpatient and outpatient diagnostic information. We also included the number of prescription drugs that the beneficiary took in 2007. We created this variable by linking the PDE file to the Medi-Span MDDB v2.5, which provides a therapeutic classification system (TCS). Specifically, this variable indicates the number of unique therapy classes based on the first 2 dig- its of Medi-Span's TCS codes. We counted drugs in the same therapeutic class as one and excluded the antihyperlipidemic class because all beneficiaries in the study sample used statins. The variable represents the burden of medications, as well as the health risk of the beneficiary. Finally, we used information from the benefit phase variable to determine if a beneficiary's total drug spending in 2007 exceeded the ICL. The "reaching ICL" variable indicates use of expensive drugs after controlling for the number of prescription drugs taken in 2007. For plan benefit variables, we used an indicator of having coverage for the gap and controlled for enrollment in an enhanced plan that offered more generous coverage than the standard benefit during the initial coverage or provided gap coverage.

\section{Results}

Of 1,342,033 Medicare Part D enrollees who filled at least 1 prescription in 2007, 553,274 (41.2\%) filled at least 1 statin prescription (Figure 1). Exclusion of those who died in 2007 or who were younger than 65 years old in 2006 resulted in 447,870 beneficiaries in the data. After exclusion of beneficiaries who did not have both Part A and Part B coverage-those with ESRD or LIS, those who were enrolled in Medicare cost or demonstration plans, and those who had missing information in explanatory variables-the counts of subjects in the unmatched (full) sample were 94,131 and 165,334 in MA-PD plans and PDPs, respectively.

Descriptive statistics for all variables used in the analysis by plan type for the unmatched sample are presented in Table 2. In the unmatched sample, beneficiaries enrolled in MA-PD plans tended to be relatively young, male, nonwhite, and resided in the West Census Region, compared with PDP enrollees. MA-PD enrollees had prescription fills for a smaller number of therapy classes and were less likely to reach the ICL in 2007, but they were more likely to enroll in an enhanced plan and have gap coverage than PDP enrollees.

The propensity score for matching was obtained from a logit analysis where the dependent variable was an MA-PD indicator. The c-statistic for the logit model was 0.57 . We excluded from the matched sample enrollees who could not be matched to a case with a propensity score within the caliper range. The matched sample included 76,922 from each plan type. Table 2 reports descriptive data for this final matched sample. The table indicates that differences in certain covariates (e.g., plan benefit, race, and census region variables) between the 2 groups were substantially reduced after matching. The table shows that all covariates in the matched sample had a standardized difference smaller than 10 , suggesting no meaningful difference in observed enrollee characteristics after matching. ${ }^{31}$

Table 3 reports statin MPRs and between-group differences for MA-PD and PDP enrollees. Analysis of mean MPR (multiplied by 100) in the unmatched sample showed no difference between the 2 groups: $70.57 \%$ for MA-PD and $70.54 \%$ for 
Comparison of Statin Adherence Among Beneficiaries in MA-PD Plans Versus PDPs

\section{TABLE 2 Descriptive Statistics for Patient Characteristics by Plan Type}

\begin{tabular}{|c|c|c|c|c|c|c|c|c|c|c|}
\hline & \multicolumn{5}{|c|}{ Unmatched (Full) Sample } & \multicolumn{5}{|c|}{ Matched Sample } \\
\hline & \multicolumn{2}{|c|}{ MA-PD } & \multicolumn{2}{|c|}{ PDP } & Std. Diff. & \multicolumn{2}{|c|}{ MA-PD } & \multicolumn{2}{|c|}{ PDP } & Std. Diff. \\
\hline n & \multicolumn{2}{|c|}{94,131} & \multicolumn{2}{|c|}{165,334} & & \multicolumn{2}{|c|}{76,922} & \multicolumn{2}{|c|}{76,922} & \\
\hline \multicolumn{11}{|l|}{ Variables } \\
\hline Age mean [SD] & 75.67 & {$[6.44]$} & 76.24 & [6.89] & 8.57 & 75.67 & [6.45] & 75.60 & [6.76] & 1.02 \\
\hline \multicolumn{11}{|l|}{ Gender \% (n) } \\
\hline Male & 39.3 & $(37,009)$ & 35.1 & $(57,979)$ & & 38.9 & $(29,910)$ & 39.2 & $(30,135)$ & \\
\hline Female & 60.7 & $(57,122)$ & 64.9 & $(107,355)$ & 8.80 & 61.1 & $(47,012)$ & 60.8 & $(46,787)$ & 1.22 \\
\hline \multicolumn{11}{|l|}{ Race/ethnicity \% (n) } \\
\hline White & 86.9 & $(81,769)$ & 94.9 & $(156,869)$ & & 90.5 & $(69,648)$ & 91.5 & $(70,400)$ & \\
\hline Black & 7.3 & $(6,840)$ & 3.4 & $(5,566)$ & 17.45 & 5.6 & $(4,314)$ & 5.4 & $(4,133)$ & 0.57 \\
\hline Asian & 1.7 & $(1,597)$ & 0.5 & (749) & 12.08 & 1.1 & $(812)$ & 0.8 & $(644)$ & 1.67 \\
\hline Hispanic/other & 4.2 & $(3,925)$ & 1.3 & $(2,150)$ & 17.66 & 2.8 & $(2,148)$ & 2.3 & $(1,745)$ & 2.52 \\
\hline \multicolumn{11}{|c|}{ Median annual household income by ZIP code levela \% (n) } \\
\hline Less than $\$ 34,000$ & 19.0 & $(17,850)$ & 24.9 & $(41,131)$ & & 19.9 & $(15,274)$ & 19.8 & $(15,195)$ & \\
\hline$\$ 34,000$ to $\$ 45,000$ & 32.9 & $(30,967)$ & 33.5 & $(55,446)$ & 1.35 & 33.4 & $(25,696)$ & 33.9 & $(26,093)$ & 0.21 \\
\hline More than $\$ 45,000$ & 48.1 & $(45,314)$ & 41.6 & $(68,757)$ & 13.20 & 46.7 & $(35,952)$ & 46.3 & $(35,634)$ & 0.19 \\
\hline $\begin{array}{l}\text { Percentage college-educated by } \\
\text { ZIP code levela mean [SD] }\end{array}$ & 16.19 & {$[8.17]$} & 15.85 & [8.66] & 4.02 & 16.16 & {$[8.23]$} & 16.15 & {$[8.43]$} & 0.26 \\
\hline \multicolumn{11}{|l|}{ Region \% (n) } \\
\hline Northeast & 25.5 & $(24,005)$ & 18.4 & $(30,434)$ & & 24.2 & $(18,597)$ & 25.4 & $(19,518)$ & \\
\hline Midwest & 15.2 & $(14,325)$ & 29.7 & $(49,158)$ & 35.31 & 18.3 & $(14,075)$ & 19.0 & $(14,610)$ & 0.41 \\
\hline South & 24.8 & $(23,316)$ & 37.8 & $(62,490)$ & 28.38 & 28.6 & $(22,023)$ & 28.1 & $(21,623)$ & 2.30 \\
\hline West & 34.5 & $(32,485)$ & 14.1 & $(23,252)$ & 49.10 & 28.9 & $(22,227)$ & 27.5 & $(21,171)$ & 0.34 \\
\hline HCC score mean [SD] & 1.05 & [0.84] & 1.07 & {$[0.86]$} & 1.99 & 1.05 & {$[0.85]$} & 1.06 & {$[0.87]$} & 0.66 \\
\hline $\begin{array}{l}\text { Number of prescription drug } \\
\text { therapy classes taken }{ }^{b} \text { mean [SD] }\end{array}$ & 7.33 & {$[4.24]$} & 7.86 & {$[4.47]$} & 12.19 & 7.44 & {$[4.34]$} & 7.47 & {$[4.31]$} & 0.95 \\
\hline Reached ICL during 2007c \% (n) & 20.0 & $(18,835)$ & 31.6 & $(52,297)$ & 26.79 & 22.3 & $(17,117)$ & 23.6 & $(18,118)$ & 3.41 \\
\hline \multicolumn{11}{|l|}{ Gap coverage $\%(\mathrm{n})$} \\
\hline Yes & 27.8 & $(26,205)$ & 18.1 & $(29,909)$ & & 26.0 & $(20,028)$ & 26.1 & $(20,052)$ & \\
\hline No & 72.2 & $(67,926)$ & 81.9 & $(135,425)$ & 55.24 & 74.0 & $(56,894)$ & 73.9 & $(56,870)$ & 0.16 \\
\hline \multicolumn{11}{|l|}{ Plan benefit \% (n) } \\
\hline Enhanced & 60.6 & $(57,067)$ & 36.7 & $(60,639)$ & & 56.6 & $(43,571)$ & 57.1 & $(43,893)$ & \\
\hline Basic & 39.4 & $(37,064)$ & 63.3 & $(104,696)$ & 49.35 & 43.4 & $(33,351)$ & 42.9 & $(33,029)$ & 0.48 \\
\hline
\end{tabular}

a Measured at the ZIP code level of a beneficiary's residence. Figures shown represent per-beneficiary means of the median income for the ZIP code and of the percentage with a college education in the ZIP code, respectively.

${ }^{b}$ Represents count of unique therapy classes used during 2007, based on the first 2 digits of the Medi-Span Master Drug Data Base classification system code (version 2.5, Wolters Kluwer Health, Indianapolis, IN; 2010).

cRepresents whether a beneficiary entered the coverage gap, where the beneficiary pays $100 \%$ of prescription costs, after spending a certain amount of drug expenditure (i.e., initial coverage limit, ICL). For the defined standard benefit, the ICL was \$2,400 in 2007.

$H C C=$ Hierarchical Condition Category; $I C L=$ initial coverage limit; $M A-P D=$ Medicare Advantage prescription drug; $P D P=$ prescription drug plan; $S D=$ standard deviation; Std. Diff. = standardized difference (the between-group difference in means divided by the square root of the average of the groups' variances).

PDP enrollees $(P=0.780)$. After propensity-score matching, statin adherence was higher among MA-PD enrollees than PDP enrollees by 1.36 percentage points (means of $70.80 \%$ vs. $69.44 \%, P<0.001$ ). In the unmatched sample, there was no between-group difference in the proportions of beneficiaries who had good adherence (MPR greater than $80 \%$ ), approximately $47 \%$ of beneficiaries in both groups $(P=0.262)$. As in the analysis of mean MPR, analysis of the propensity-score matched sample showed that statin adherence was better among MA-PD enrollees (47.0\%) than PDP enrollees (45.3\%), a difference of 1.7 percentage points $(P<0.001)$.

\section{Discussion}

Medicare prescription drug coverage is offered through MA-PD plans or PDPs, which differ in the breadth of coverage of health services. One model of health service use described earlier has proposed that efficient use of services is achieved when one insurer, such as an MA-PD plan, provides coverage for all types of substitutable services. ${ }^{1}$ Analyzing data from a random sample of Medicare Part D enrollees, we found that MA-PD enrollees had slightly better statin adherence than beneficiaries in PDPs.

Although statin adherence was slightly higher among 
MA-PD enrollees than PDP enrollees-by 1.36 percentage points in MPR—on average, the difference corresponds to only about 5 additional days of therapy per year $(0.0136 \times 365$ days $)$. This small difference in statin adherence, while statistically significant, is unlikely to result in different clinical outcomes.

The probability of having good statin adherence (MPR greater than 80\%) was higher among MA-PD enrollees than PDP enrollees by 1.7 percentage points. We identified about 165,000 statin users in PDPs in a dataset that represented 5\% of Part D enrollees in 2007. This finding implies that about 3.3 million non-LIS, elderly PDP beneficiaries with both Part A and Part B coverage were taking a statin in 2007. Thus, if PDP enrollees had matched the performance of the MA-PD enrollees, about 58,000 more people would have been adherent to statin medications. However, as in the analysis of mean MPR, the difference was statistically significant but very small. The analysis also found that the proportion of Part D enrollees who had good statin adherence in 2007 was less than 50\% in both MA-PD plans and PDPs. This finding suggests that there is much room for Medicare beneficiaries in both types of Part D plans to make improvements in statin use. Given the clinical significance of statin treatment in preventing and managing CHD, ${ }^{14-16}$ it is important to continuously assess and ensure statin adherence among Medicare Part D beneficiaries.

The primary study finding_clinically negligible differences in statin adherence between the 2 types of plans-did not support the hypothesis that enrollees in MA-PD plans, in which medical and pharmacy benefits are integrated, would have better medication adherence than enrollees in stand-alone PDPs. A possible reason for this finding is that many MA-PD plans may contract with pharmacy benefit management (PBM) companies to control the cost and utilization of prescription drugs. This outsourcing of drug utilization management to another entity may weaken the degree of organizational integration of MA-PD plans in providing pharmacy services, except that MA-PD plans continue to determine pharmacy benefit designs. Further, PDPs may contract with PBMs; thus, similar tools to manage drug utilization may have applied to both MA-PD and PDP members. For example, a prior study described a PBM's implementation of an intervention to increase statin use by all its Medicare Part D MA-PD or PDP members who met criteria for medication therapy management and had either diabetes or coronary artery disease. ${ }^{34}$

The results of the present study may also reflect a betweengroup difference in reasons for taking statins. Statin adherence has been shown to be lower among statin users without prior cardiovascular diseases than those with prior cardiovascular events. ${ }^{35} \mathrm{~A}$ prior study showed that MA-PD enrollees are relatively healthier than PDP enrollees. ${ }^{29}$ It is possible that a larger proportion of MA-PD enrollees may have used statins for primary prevention than PDP enrollees. This possibility may have contributed to the small difference we found in our

\section{TABLE 3 Medication Possession Ratio} Measures by Plan Type

\begin{tabular}{|c|c|c|c|}
\hline & $\begin{array}{l}\text { Percentage } \\
\text { Point } \\
\text { Difference }\end{array}$ & MA-PD & PDP \\
\hline \multicolumn{4}{|l|}{ Unmatched (full) sample } \\
\hline Number of cases & & 94,131 & 165,334 \\
\hline Mean [SD] MPR & 0.03 & $70.57[27.31]$ & $70.54[27.24]$ \\
\hline Percentage (n) adherent ${ }^{\mathrm{a}}$ & 0.2 & $46.7(43,948)$ & $46.9(77,569)$ \\
\hline \multicolumn{4}{|l|}{ Propensity-matched sample } \\
\hline Number of cases & & 76,922 & 76,922 \\
\hline Mean [SD] MPR & $1.36^{\mathrm{b}}$ & $70.80[27.20]$ & $69.44[27.73]$ \\
\hline Percentage (n) adherent ${ }^{\mathrm{a}}$ & $1.7^{\mathrm{b}}$ & $47.0(36,172)$ & $45.3(34,813)$ \\
\hline \multicolumn{4}{|c|}{$\begin{array}{l}\text { adherence was defined as MPR exceeding } 80 \% \text {. } \\
b P<0.001 \text { using independent-sample t-test for MPR and Pearson chi-square test for } \\
\text { percentage adherence. } \\
M A-P D=\text { Medicare Advantage prescription drug; MPR = medication possession } \\
\text { ratio; } P D P=\text { prescription drug plan; } S D=\text { standard deviation. }\end{array}$} \\
\hline
\end{tabular}

analysis. We could not examine this because we did not have information on the specific clinical indication for statin use in our data, although we controlled for general health risk measures in our model.

We are not aware of previous research that compared statin adherence between MA-PD plans and PDPs; however, the MPR and share of beneficiaries with good adherence obtained in the present study analysis appear to be within the range reported in the literature. A previous study reported that mean MPR of prescription drugs for hyperlipidemia among Medicare beneficiaries in an MA-PD during the first 2 years of the Part D program was between $60 \%-73 \%$, depending on drug benefit schemes that the beneficiaries had prior to the implementation of the Part D program. ${ }^{11}$ It also found that between $43.9 \%$ $61.3 \%$ of beneficiaries in the MA-PD plan had good adherence (MPR greater than $80 \%$ ), depending on their drug benefit policies prior to the Part D program. ${ }^{11}$ The present study found that both MA-PD plan and PDP enrollees had a similar level of statin adherence during an early year of the Part D program.

With the increasing clinical importance of prescription drugs, identifying factors that contribute to the use of and adherence to prescription drugs has been of interest, and a large body of the literature has examined the role of cost sharing. ${ }^{10}$ However, many factors affect drug adherence. ${ }^{6} \mathrm{~A}$ review study indicates that major predictors of poor drug adherence include inadequate follow-up, patients' lack of belief in or information about the benefit of treatment, poor provider-patient relationship, other competing demands, and other factors. ${ }^{36}$ Working on all these aspects (e.g., frequent follow-up, improving patients' knowledge on the benefits of drug adherence) may effectively improve the use of appropriate medications. It is also important to examine mechanisms by which Part D plans improve adherence to recommended medications. A recent 
study reported that a 2-part intervention, consisting of letters sent to primary care physicians with patient-specific medication profiles and general medication adherence letters mailed to potentially nonadherent patients, was associated with improvement in adherence. ${ }^{37}$ Similar approaches could be introduced to increase the use of prescription drugs by all types of Part D plans. These efforts to increase medication adherence will increase direct pharmacy costs but have the potential to reduce total costs if the increased pharmacy costs are offset by lower medical costs.

\section{Limitations}

First, although we used propensity-score matching analysis to address differences in observed patient characteristics between MA-PD and PDP enrollees, selection bias may remain if there are unmeasured characteristics that differ by plan type and affect statin adherence. The propensity-score matching approach reduces bias by ensuring similarities in observable characteristics between the 2 groups being compared; however, the low c-statistic of 0.57 indicates that the propensity-score model poorly predicted MA-PD enrollment. Our analysis obtained a matched sample based on several important covariates that influence plan selection and statin adherence, including diagnoses-based health-risk measures and plan benefit variables. However, the exact cost-sharing level for statin use is a potentially important omitted variable in our model. We accounted for the general benefit scheme of each plan; however, Part D plans can modify the cost-sharing amount for each prescription drug as long as their benefit schemes overall are actuarially equivalent. Although patient cost is a field in the PDE file, we did not assess out-of-pocket costs for statin use, which may vary across plans and might influence statin adherence.

Second, the present study was limited to assessing statin adherence rates during an early year of the Part D program. Differences in statin adherence between the 2 types of plans may have changed over the years as Medicare Part D plans gained experience with medication adherence promotion, member satisfaction, and the costs of providing prescription drug and/or medical benefits.

Third, our analysis did not account for the possibility of switching to other lipid-lowering drugs from statins, and beneficiaries who continued their treatment using other lipid-lowering medications would have been considered as nonadherent to statins. Because statins are widely accepted as one of the most effective lipid-lowering drug treatments, switching to other lipid-lowering drugs is unlikely. However, if switching to other lipid-lowering medications were recommended by physicians as a better approach to improve patients' health outcomes, our study might overestimate the degree of drug nonadherence.

Finally, our results may not be generalizable to other therapeutic classes. Drugs in certain therapeutic classes may be more likely to be subject to aggressive utilization management tools than statins due to their high costs. Further, if guidelines of drug therapy for some therapeutic classes are not as established as they are for statins ${ }^{38}$ the clinical evidence for improving adherence to those medications may be limited.

\section{Conclusions}

MA-PD plan enrollees had slightly higher adherence to statins than PDP enrollees during an early year of the Part D program. While the difference was statistically significant, it was very small and unlikely to lead to clinically meaningful consequences. Less than one-half of Medicare Part D enrollees had "good adherence" to statin therapy, suggesting much room for improvement in statin adherence by Medicare Part D beneficiaries. As prescription drugs play an increasingly important role in treating or managing chronic conditions, continuing evaluation of medication adherence among Medicare beneficiaries will help ensure that all types of Part D plans make efforts to improve drug adherence.

\section{Authors}

KYOUNGRAE JUNG, PhD, is Assistant Professor, Department of Health Policy and Administration, The Pennsylvania State University College of Health and Human Development, University Park, Pennsylvania; A. MARSHALL MCBEAN, MD, MSc, is Professor; and JEE-AE KIM, MPP, is a PhD candidate, Division of Health Policy and Management, University of Minnesota School of Public Health, Minneapolis, Minnesota.

AUTHOR CORRESPONDENCE: Kyoungrae Jung, PhD, Pennsylvania State University Health Policy and Administration, 601H Ford Bldg., University Park, PA 16802. Tel.: 814.863.8129; E-mail:kuj11@psu.edu.

\section{DISCLOSURES}

The authors report no financial or other potential conflicts of interest. This project was supported by the Centers for Medicare and Medicaid Services contract HHSM-500-2005-00271.

Jung and McBean designed the study, and McBean obtained the data Kim cleaned and analyzed the data. Jung interpreted the data and wrote and revised the manuscript, with the assistance of McBean and Kim.

\section{REFERENCES}

1. Goldman D, Philipson TJ. Integrated insurance design in the presence of multiple medical technologies. Am Econ Rev. 2007;97(2):427-32.

2. Chandra A, Gruber J, McKnight R. Patient cost-sharing and hospitalization offsets in the elderly. Am Econ Rev. 2010;100(1):193-213. Available at: http://www.ncbi.nlm.nih.gov/pmc/articles/PMC2982192/?tool=pubmed. Accessed January 25, 2012

3. Manning WG, Newhouse JP, Duan N, Keeler EB, Leibowitz A. Health insurance and the demand for medical care: evidence from a randomized experiment. Am Econ Rev. 1987;77(3):251-77. 
4. Cammisa CR, Evans S, Fenter TC, et al. Overview of current Medicare Part D offerings. J Manag Care Pharm. 2008;14(6) (suppl S-C):S4-S7. Available at: http://www.amcp.org/data/jmcp/Aug\%20suppl\%20C_S4-S7.pdf.

5. Medicare Payment Advisory Commission. Report to the Congress: Medicare payment policy. March 2008. Available at: http://www.medpac. gov/documents/Mar08_EntireReport.pdf. Accessed January 25, 2012.

6. Fairman KA, Curtiss FR. How do seniors respond to $100 \%$ cost-sharing for prescription drugs? Quality of the evidence underlying opinions about the Medicare Part D coverage gap. J Manag Care Pharm. 2011;17(5):382-92. Available at: http://www.amcp.org/WorkArea/DownloadAsset.aspx?id=9734.

7. Hoadley J, Hargrave E, Cubanski J, Neuman T. The Medicare Part D coverage gap: costs and consequences in 2007. The Henry J. Kaiser Family Foundation. August 2008. Available at: http://www.kff.org/medicare/ upload/7811.pdf. Accessed January 25, 2012.

8. Fung V, Mangione CM, Huang J, et al. Falling into the coverage gap: Part $\mathrm{D}$ drug costs and adherence for Medicare Advantage prescription drug plan beneficiaries with diabetes. Health Serv Res. 2010;45(2):355-75.

9. Tseng CW, Brook RH, Keeler E, Steers WN, Mangione CM. Cost-lowering strategies used by Medicare beneficiaries who exceed drug benefit caps and have a gap in drug coverage. JAMA. 2004;292(8):952-60. Available at: http:// jama.ama-assn.org/content/292/8/952.full.pdf+html. Accessed January 25, 2012.

10. Gemmill MC, Thomson S, Mossialos E. What impact do prescription drug charges have on efficiency and equity? Evidence from high-income countries. Int J Equity Health. 2008;7:12. Available at: http://www.equityhealthj.com/content/pdf/1475-9276-7-12.pdf. Accessed January 25, 2012.

11. Zhang Y, Lave JR, Donohue JM, Fischer MA, Chernew ME, Newhouse JP. The impact of Medicare Part D on medication adherence among older adults enrolled in Medicare-Advantage products. Med Care. 2010;48(5):409-17.

12. Yin W, Basu A, Zhang JX, Rabbani A, Meltzer DO, Alexander GC. The effect of the Medicare Part D prescription benefit on drug utilization and expenditures. Ann Intern Med. 2008;148(3):169-77. Available at: http://www. annals.org/content/148/3/169.full.pdf+html. Accessed January 25, 2012.

13. Medicare Payment Advisory Commission. A data book: Medicare Part D program. March 2010. Available at: http://www.medpac.gov/documents/ Mar10_PartDDataBook.pdf. Accessed January 25, 2012.

14. Shepherd J, Cobbe SM, Ford I, et al.; for the West of Scotland Coronary Prevention Study Group. Prevention of coronary heart disease with pravastatin in men with hypercholesterolemia. N Engl J Med. 1995;333(20):1301-07. Available at: http://www.nejm.org/doi/full/10.1056/NEJM199511163332001. Accessed January 25, 2012.

15. Downs JR, Clearfield M, Weis S, et al.; for the AFCAPS/TexCAPS Research Group. Primary prevention of acute coronary events with lovastatin in men and women with average cholesterol levels: results of AFCAPS/ TexCAPS. JAMA. 1998;279(20):1615-22. Available at: http://jama.ama-assn. org/content/279/20/1615.full.pdf+html. Accessed January 25, 2012.

16. Lloyd-Jones D, Adams R, Carnethon M, et al.; for the American Heart Association Statistics Committee and Stroke Statistics Subcommittee. Heart disease and stroke statistics_2009 update. A report from the American Heart Association Statistics Committee and Stroke Statistics Subcommittee. Circulation. 2009;119(3):480-86. Available at: http://circ. ahajournals.org/content/119/3/e21.full.pdf. Accessed January 25, 2012.

17. Goldman DP, Joyce GF, Karaca-Mandic P. Varying pharmacy benefits with clinical status: the case of cholesterol-lowering therapy. Am J Manag Care. 2006;12(1):21-28. Available at: http://www.ajmc.com/media/pdf/ AJMC_06janGoldman21to28.pdf. Accessed January 25, 2012

18. Gibson TB, Mark TL, Axelsen K, Baser O, Rublee DA, McGuigan KA Impact of statin copayments on adherence and medical care utilization and expenditures. Am J Manag Care. 2006;12 Spec no:SP11-9. Available at: http:// www.ajmc.com/media/pdf/AJMC_06DecspeclGibsonSP11.pdf. Accessed January 25, 2012.
19. Medi-Span Master Drug Data Base (MDDB) version 2.5: Wolters Kluwer Health, Inc., Indianapolis, IN; 2010.

20. Pope GC, Kautter J, Ellis RP, et al. Risk adjustment of Medicare capitation payments using the CMS-HCC model. Health Care Financ Rev. 2004;25(4):119-41. Available at: https://www.cms.gov/ HealthCareFinancingReview/downloads/04Summerpg119.pdf. Accessed January 25, 2012

21. Andrade SE, Kahler KH, Frech F, Chan KA. Methods for evaluation of medication adherence and persistence using automated databases. Pharmacoepidemiol Drug Saf. 2006;15(8):565-74

22. Karve S, Cleves MA, Helm M, Hudson TJ, West DS, Martin BC. An empirical basis for standardizing adherence measures derived from administrative claims data among diabetic patients. Med Care. 2008;46(11):1125-33.

23. Avorn J, Monette J, Lacour A, et al. Persistence of use of lipid-lowering medications: a cross-national study. JAMA. 1998;279(18):1458-62. Available at: http://jama.ama-assn.org/content/279/18/1458.full.pdf+html. Accessed January 25, 2012

24. Benner JS, Glynn RJ, Mogun H, Neuman PJ, Weinstein MC, Avorn J. Long-term persistence in use of statin therapy in elderly patients. JAMA. 2002;288(4):455-61. Available at: http://jama.ama-assn.org/content/288/4/455.full.pdf+html. Accessed January 25, 2012.

25. Insull $\mathrm{W}$. The problem of compliance to cholesterol altering therapy. $J$ Intern Med. 1997;241(4):317-25. Available at: http://onlinelibrary.wiley.com/ doi/10.1046/j.1365-2796.1997.112133000.x/pdf. Accessed January 25, 2012.

26. Pladevall M, Williams LK, Pott LA, Divine G, Xi H. Lafata JE. Clinical outcomes and adherence to medications measured by claims data in patients with diabetes. Diabetes Care. 2004;27(12):2800-05. Available at: http://care. diabetesjournals.org/content/27/12/2800.full.pdf+html. Accessed January 25, 2012.

27. Riley GF, Levy JM, Montgomery, MA. Adverse selection in the Medicare prescription drug program. Health Aff (Millwood). 2009;28(6):1826-37.

28. Rosenbaum PR, Rubin DB. The central role of the propensity score in observational studies for causal effects. Biometrika. 1983;70(1):41-55. Available at: http://biomet.oxfordjournals.org/content/70/1/41.full.pdf+html. Accessed January 25, 2012.

29. Rosenbaum PR, Rubin DB. Constructing a control group using multivariate matched sampling methods that incorporate the propensity score. Am Stat. 1985;39(1):33-38.

30. Becker SO, Ichino A. Estimation of average treatment effects based on propensity scores. Stata J. 2002;2(4):358-77. Available at: http://www.statajournal.com/sjpdf.html?articlenum=st0026. Accessed January 25, 2012.

31. Austin PC. Balance diagnostics for comparing the distribution of baseline covariates between treatment groups in propensity-score matched samples. Stat Med. 2009;28(25):3083-107.

32. Normand ST, Landrum MB, Guadagnoli E, et al. Validating recommendations for coronary angiography following an acute myocardial infarction in the elderly: a matched analysis using propensity scores. J Clin Epidemiol. 2001;54(4):387-98.

33. Austin PC. Primer on statistical interpretation or methods report card on propensity-score matching in the cardiology literature from 2004 to 2006: a systematic review. Circ Cardiovasc Qual Outcomes. 2008;1(1):62-67. Available at: http://circoutcomes.ahajournals.org/content/l/1/62.full.pdf+html. Accessed January 25, 2012.

34. Stockl KM, Tjioe D, Gong S, Stroup J, Harada AS, Lew HC. Effect of an intervention to increase statin use in Medicare members who qualified for a medication therapy management program. J Manag Care Pharm. 2008;14(6):532-40. Available at: http://www.amcp.org/data/jmcp/ JMCPMaga_532-540.pdf.

35. Foody JM, Joyce AT, Rudolph AE, Liu LZ, Benner JS. Persistence of atorvastatin and simvastatin among patients with and without prior cardiovascular: a U.S. managed care study. Curr Med Res Opin. 2008;24(7):1987-2000. 
36. Osterberg L, Blaschke T. Adherence to medication. N Engl J Med. 2005;353(5):487-97.

37. Jing S, Naliboff A, Kaufman MB, Choy M. Descriptive analysis of mail interventions with physicians and patients to improve adherence with antihypertensive and antidiabetic medications in a mixed-model managed care organization of commercial and Medicare members. J Manag Care

Pharm. 2011;17(5):355-66. Available at: http://www.amcp.org/WorkArea/ DownloadAsset.aspx?id=9731
38. National Institutes of Health. National Heart, Lung, and Blood Institute. Third report of the National Cholesterol Education Program (NCEP) expert panel on detection, evaluation, and treatment of high blood cholesterol in adults (adult treatment panel III). Final report. NIH Publication No. 02-5215. September 2002. Available at: http://www.nhlbi.nih.gov/guidelines/ cholesterol/atp3full.pdf. Accessed January 25, 2012. 